\title{
Kazuo Ishiguro's Nocturnes: Between Archive and Repertoire
}

\section{Introduction}

The Nobel Prize in Literature is not associated with the short story: only Alice Munro, recipient of the Nobel Laureateship in 2013, has been recognised for her contribution to the form. Even then, as Adrian Hunter has rightly noted, Munro's short stories tended to be treated as if they were novels: 'the dust-jackets of her books overflow with testimony to the novel-like qualities of the stories, their satisfying range and depth and complexity of characterization. It is as though Munro is to be considered a great writer in spite of the fact that she only writes short stories' (165; original emphasis). Kazuo Ishiguro was awarded the Nobel Prize for Literature in 2017, in recognition of his achievements as a novelist. Ishiguro's Nobel lecture, published as My Twentieth-Century Evening and Other Small Breakthroughs (2017), referred to his early short stories as apprentice pieces, written hurriedly upon hearing the news that he had been accepted onto the creative-writing programme at the University of East Anglia (3-4). Ishiguro made no reference in the lecture to his more recent collection of stories, Nocturnes: Five Stories of Music and Nightfall (2009). Indeed, Sebastian Groes and Barry Lewis have noted that its publication had come as something of a surprise, given that Ishiguro had explicitly stated that he used the short story as a means of testing ideas, observing in interview with Sean Matthews: 'I often write things that aren't really short stories in a way that Alice Munro or Chekhov wrote short stories. These are just pieces that end quite quickly, and sometimes these things find their way into my novels' (122). Taking Nocturnes as its focus, this essay asks how we might read the five stories contained in the collection in the context of Ishiguro's broader oeuvre. How might we fit them into Ishiguro's wider creative practice as a writer? 
One starting point might be to take a closer look at Ishiguro's Nobel lecture. The story that he tells there of his own coming-of-age as a writer entails both a movement away and a movement towards. Ishiguro departs from his early experiments with the short story even as he begins to write, 'with a new and urgent intensity', about Japan, and more specifically about Nagasaki, the city of his birth (4). Hunter has discussed the short-story form in relation to Gilles Deleuze and Felix Guattari’s 1975 study Kafka: Toward a Minor Literature. Defined as a mode of writing that the minority constructs within a major language, minor literature signals its own displacement and strangeness. Hunter regards this theory to be applicable to the short story because it provides a positive lens through which to view the form's minority status. The short story's lack of determination or of closure can be read as a resistance to power, although Hunter makes clear that the short story does not uniquely, or inherently, fulfil a minority function. Where the short story has excelled, Hunter observes, is as a 'medium for communicating the sense of chronic inconsequence' (141). This latter phrase could hardly be bettered as a description of Ishiguro's oeuvre. There are several directions of thought that might be pursued here. Ishiguro's lecture tells a story of substituting one mode of minority literature — the short story — for another: a novel in English that explores his Japanese inheritance. Turning to the subject matter of Japan felt, in the literary climate of the time, to be 'a self-indulgence', and the majority form of the novel in English supplied Ishiguro with a medium through which to express his sense of estrangement. Alternatively, we could ask whether Ishiguro did indeed leave the short story behind, or if he imported its strategies and techniques into the novel form. This, too, would create a sense of disquiet, an unsettling strangeness. This approach chimes with Christine Reynier's reading of Virginia Woolf's short stories, not as 'mere laboratories leading to the writing of novels' but as generically hybrid works that weave through and grow out of the novels, 'raising the problem of the autonomy of the novel and of its complete or incomplete nature' (8). To what 
extent, then, do Ishiguro's short stories become integrated into, or even emerge out of, the novels, blurring the distinction between genres?

A second starting point lies in Brian W. Shaffer's essay on Ishiguro's early short stories, which challenges the critical consensus that they should be dismissed 'as juvenilia or as amateur experiments that merit attention only as sketches towards the more mature and accomplished novels' (9). Arguing for an 'organic connection' between the early short stories and the later novels, Shaffer sees in 'Waiting for J' and 'Getting Poisoned' 'a key to understanding the psychological trauma ... at the heart of all of Ishiguro's narratives', while he observes that Ishiguro wrote 'A Village in the Dark' to 'work out certain narrative techniques he was exploring while writing The Unconsoled' (11). Published in the same year as Nocturnes, Shaffer's study does not address the later short-story collection. Nevertheless, his reading is suggestive when approaching the latter work. Shaffer's observation that, when encountering Fletcher in 'A Village in the Dark' it is 'impossible not to think of Ryder' (11; original emphasis), confronts us again with the permeability of forms, and the leakage of characters, techniques, themes and plots across and between them. There has been a tendency in criticism on Ishiguro to read only across the novels, and little work has yet been done to connect the novels with Ishiguro's other modes of writing. I accordingly ask how we might look at Ishiguro's oeuvre from the perspective of the short stories.

In approaching Nocturnes, I am interested in the archive and the repertoire. The archive refers to a public building where records are kept, and Ishiguro's oeuvre has now been absorbed into the literary archival collections of the Harry Ransom Center, at the University of Texas in Austen. ${ }^{1}$ Catalogued and curated, Ishiguro's notes and drafts are captured and stored for posterity. Ishiguro's writing in Nocturnes evidences a fascination with the repertoire of twentieth-century American musical standards: their selection, their memorisation, and their transmission. This varied interest points us towards Ishiguro's own creative practice as 
lyricist, most notably in collaboration with jazz singer Stacey Kent. ${ }^{2}$ It also leads us towards Ishiguro's broader interest in the repertoire as a system of performed, embodied, and iterative behaviours through which knowledge is transmitted. Diana Taylor has summarised the repertoire as follows:

The repertoire ... enacts embodied memory ... [It is], in short, all those acts usually thought of as ephemeral, non-reproducible knowledge ... The repertoire requires presence: people participate in the production and reproduction of knowledge by 'being there', being a part of the transmission. As opposed to the supposedly stable objects in the archive, the actions that are the repertoire do not remain the same. (20)

For Taylor, the repertoire, transmitted through performance, offers an important means of access to individual and collective life, because of its ability to 'tap into public fantasies and leave a trace, reproducing and at times altering cultural repertoires' (143). I argue in what follows that this is one aspect of Ishiguro's interest in the repertoire: working against the 'depth' model of the archive, Ishiguro examines the ways in which any singularity that we might possess is, at best, the modification of a received repertoire. However, Taylor also challenges the binary opposition of archive and repertoire, noting: 'There is a continuum of ways of transmitting memory that spans from the archival to the embodied ... with all sorts of mediated and mixed modes in between' (192). In reading Nocturnes, I will trace Ishiguro's fascination with different modes of transmitting and receiving knowledge, and his careful documentation of the diverse range of cultural forms that lie between archive and repertoire.

\section{The short story and repertoire}


In his essay on the Kazuo Ishiguro archive at the Harry Ransom Center, Stephen Ennis includes Ishiguro's description of the archive's origins in his everyday writing practice:

For many years, I've been in the habit of keeping a large cardboard box under my desk into which I throw, more or less indiscriminately, all papers produced during my writing that I don't want to file neatly and take into the next stage of composition: earlier drafts of chapters, rejected pages, scraps of paper with scribbled thoughts, repeated attempts at the same paragraph, etc. (no pagination)

This description is reminiscent of the opening of Amy Hungerford's Making Literature Now (2016), in which she details rummaging through cardboard boxes in the basement offices of McSweeney's, which contained 'the drafts, proofs, and correspondence of the press's disorganized archive' (1). Hungerford uses these overflowing cardboard boxes to make the point that the making of contemporary literature takes place through broad 'networks of makers, objects and acts' (2). Scholarly conventions tend to centre on a small group of figures, a shared canon of reading that becomes the object of study in twenty-first century literary culture. Hungerford's shift in focus from the maker - the celebrated author - to the process of making brings into view ideas, products, readers, institutions and workers that are 'culturally invisible', but that are nevertheless essential to capturing the broader field of activity through which literary reputations are created and sustained (16).

Hungerford returns to the cardboard box in her 'Afterword', noting that it has now been absorbed into the archive: 'less than three years after I rummaged in the McSweeney's basement, ... everything ... in those boxes w[as] bought by the Harry Ransom Center at the University of Texas, Austen' (170). The ephemeral has become permanent: organised and curated, it has been made available as a new object of study in the contemporary literature canon. Hungerford remarks, however, that there is a remnant that cannot be captured in or by 
the archive: 'the context recoverable by live conversation cannot be archived even by a wellendowed center - or rather, it can't be archived until context materializes in an artifact' (170). The diverse social conversations in and through which contemporary literature is shared and shaped are often performed, embodied and non-reproducible - they are, in other words, more proximate to the repertoire than to the archive.

Returning to the cardboard box under Ishiguro's desk, we might note that what the Ishiguro archive makes available for study emphasises the centrality of the maker. Emerging out of the draft material that didn't make it into the final cut, this archive might be seen to reinforce an understanding of the published work as autonomous and independent. Ishiguro has added extensive notes to the draft material, which curate a narrative of his personal development as a writer. Ennis has remarked of the Ishiguro archive: 'All archives are negotiations with the past, but rarely does one dramatize so fully the play of memory and its intimate ties to the novelist's art' (no pagination). Focused on manuscripts and unpublished juvenilia, the Ishiguro archive does not capture the networks of publishers, book designers and distributors, literary festival organisers, reviewers and readers, who have contributed to shaping Ishiguro's reputation. Following Hungerford, we might reflect that, while the contemporary literary archive preserves what is already in the box, it does not often contain the social, business, and media networks that also underpin the processes of literary production and reception. The literary archive, in other words, excludes the ephemeral material of the repertoire.

The archive can act in opposition to the repertoire, reinforcing and consolidating a majority literature, but it can also exist in a continuum with it. In an interview with Boyd Tonkin, Ishiguro reflected on the intimate relationship between the stories in Nocturnes and the standards of the American songbook. The songs played by the characters in the stories hark back to the great American singers from the nineteen-forties and -fifties_-Ella Fitzgerald, Frank Sinatra, Carmen McRae — and are evocative of a particular time and place: 'We are on 
a rather romantic American highway, and this is just one of those things that happen by the side of the road. You take a drink, you have an uplifting bittersweet conversation with the bartender, you get back on the highway and you carry on' (no pagination). Ishiguro's stories seek to capture the feel and the mood conjured by the American standards. His return to the songs listened to by his parents' generation is accordingly no mere exercise in nostalgia; rather, Ishiguro is interested in the American songbook as a repertoire that is constantly being reinterpreted. He observes to Tonkin that focusing attention on the repertoire - the embodied transmission of knowledge through performance — can destabilise the archive: 'Yesterday's corn, reworked by a maestro of today, becomes tomorrow's canon. The musician's regenerating skill can put a stamp of immortality on some time-worn ballad or torch song' (no pagination). At the heart of Nocturnes, then, lies an interest in the different modes through which musical knowledge is passed on, as well as with how the method of transmission can influence what is remembered and what becomes forgotten.

Music is the main theme of the short-story collection, but Nocturnes also comprises what Gerry Smyth has termed 'a musical text' (152). Smyth refers to the stylistic features of the collection that 'imitate musical forms and/or compositional procedures within a literary context': he includes 'repetition with variation, evenness of tone, [and] the manipulation of meaning at the material level of the signifier', all of which 'function with reference to common musical properties and effects' (152). In a Guardian interview with Decca Aitkenhead, Ishiguro goes further, blurring the boundaries between the short stories and music in a number of suggestive ways. Ishiguro begins with style, observing that there is a 'natural evolution' from writing songs to writing fiction, and that his characteristic 'pared down' style is 'like a songwriter' (no pagination). He then describes Nocturnes through analogy with musical form: summarising the collection as a fictional work in five movements, Ishiguro turns to the sonata, in which 'you get five what seems like totally 
separate pieces of music but they go together' (no pagination). Here, Ishiguro captures the interconnectedness of the stories, which works at a variety of levels: character, setting, symbol, and style. Nocturnes is one of a number of recent British collections of short fiction that have centred on a single theme or setting. ${ }^{3}$ Individual stories can be read in isolation, but they gain in depth and complexity through echoes of other stories in the collection. Ishiguro's musical comparison suggests that there is also an important flow to the reading experience, which moves through different moods and tonalities. In a second musical analogy, Ishiguro reflects that the more accurate resemblance would be with 'an album' - and more particularly with the concept album - in which individual tracks explore a single idea and comprise 'more than the sum of their parts' (no pagination). ${ }^{4}$ Ishiguro gestures towards a form that creates deliberate shifts in mood and tone, and he also evokes a mode of transmission that characterises the musical experience of his own generation: 'I'm still a pre-iPod person. I think of contemporary music in terms of albums' (no pagination). Ishiguro's interest in the technology of transmission is also evident in the stories, and continues his fascination in Never Let Me Go (2005) with the record and the cassette tape.

'Crooner', the opening story of Nocturnes, immediately focuses our attention on repertoire. The narrator, Janeck, is a jobbing musician on Venice's Piazzo San Marco, and he rotates around the bands that play on the square. The repertoire of tunes is dictated by tourist demand: 'What tourists can't take too much of is the classical stuff, all these instrumental versions of famous arias. ... [E]very few minutes they want something they recognise, maybe an old Julie Andrews number, or the theme from a famous movie' (4-5). When Janeck recognises the American crooner Tony Gardner sitting at one of the café tables, he recalls his mother's treasured collection of Gardner's records, painstakingly acquired as they were not readily available in communist Poland. The records conjure for Janeck his mother's flat, where she listened to them and cried for a life that could not be hers. The album covers are as 
important in evoking the past for Janeck as the songs on the records: he recalls of his mother, 'the way I'd come into the room and see her on the sofa gazing at her record sleeve with its picture of an American road, or maybe of the singer sitting in an American car' (27). Gardner's records embody Janeck's mother's yearning for an American capitalist lifestyle that is out of reach. When Janeck introduces himself to Gardner, he likewise conjures the past for him by describing album sleeves for Gardner to identify. Although the records evoke vivid memories for Janeck and Gardner, their outdated technology speaks to Gardner's unfashionable status: if people do still recognise him, it is only as 'some crooner from a bygone era' (16). The mode of transmitting music has moved on, and so has market demand. Unlike Janeck, Gardner has not adapted himself to the tastes of the current musical market. As the story unfolds, we learn that Gardner and his wife Lindy are in Venice because they have decided to divorce, so that Gardner can stage a comeback. Gardner recruits Janeck to accompany him on the guitar, as he serenades Lindy from a gondola with a selection of songs from his repertoire. Playing beside Gardner in the unsteady gondola, Janeck recognises the maestro in his performance: 'his voice came out just as I remembered it - gentle, husky, but with a huge amount of body, like it was coming through an invisible mike. And like all the best American singers, there was that weariness in his voice, even a hint of hesitation, like he's not a man accustomed to laying open his heart this way. That's how all the greats do it' (27). When Lindy sobs, Gardner explains to Janeck that they are both sad because they still love each other: unlike in the songs, where people who 'go on loving each other ... stay together forever' (31), their marriage is no longer viable in a world dictated by market forces. Lindy surfaces again in 'Nocturne' when the narrator, Steve - a jobbing jazz musician who has undergone plastic surgery to enhance his musical career-finds himself in a neighbouring hotel room, as Lindy, too, has just had cosmetic surgery in order to attract a new husband. Encased in bandages, and bored of putting 'one CD after another into the Bang \& Olufsen' 
(136), Steve accepts an invitation to Lindy's room, even though she represents for him 'everything that was shallow and sickening about the world' (137). After establishing that Steve is a saxophonist, Lindy puts on a CD of Gardner's music, choosing a song that Steve 'just about remembered' and 'which no one plays much any more' (142). In a scene that recalls Kathy H. dancing to Judy Bridgewater's version of 'Never Let Me Go', Steve observes Lindy 'in front of me, gone into a kind of dream, dancing slowly to the song' (142). When Lindy invites Steve to play one of his own tracks, he selects 'The Nearness of You', in which 'I rise up in intervals you'd never believe possible and then hold that sweet, very tender high B-flat. I think there are colours there, longings and regrets, you won't have come across before' (154). Lindy invites Steve back to play the track to her a second time and she then presents him with a trophy for 'Jazz Musician of the Year', which she has stolen from the award ceremony that is taking place downstairs in the hotel. As in Never Let Me Go, the song opens up a desire to be held; a need that seemingly cannot be fulfilled because of the capitalist forces that impinge upon it. Kathy H.'s cassette tape at Hailsham embodied her life as copy and as currency; the CDs played on the Bang \& Olufsen system of the luxury hotel equally speak of Lindy's - and Steve's - subservience to the market, with its insatiable demand for the new that has rendered them literally faceless to one another. ${ }^{5}$

Music can be transmitted through various recording technologies, but it is often passed on in embodied performances that require presence. 'Cellists', the closing story of the collection, returns to the setting of Venice. The narrator tells the story of Tibor, a classically trained Hungarian cellist who has fallen on hard times and is 'forced to perform music he hate[s]' (192). Tibor is taken up by an American tourist, Eloise McCormack, who claims to be a virtuoso cellist and offers him instruction. Eloise teaches Tibor by listening to passages of his playing, and then explaining how he could improve. Under her tutelage, Tibor's playing does 
get better. However, Tibor learns that Eloise has not, in fact, played the cello since she was eleven years old. Reflecting on Eloise's pedagogical technique, Tibor observes:

'I think it works well, what we've always done. You suggest verbally, then I play. That way, it's not like I copy, copy, copy. Your words open windows for me. If you played yourself, the windows would not open. I'd only copy.' (208)

Eloise and Tibor share a vision of music that opens up new possibilities in Tibor's playing. Yet there remains something surreal, if not disturbing, about the disembodiment of Eloise's musicianship: she is so absorbed in the ideal of the virtuoso musician that she is unwilling to compromise her talent through practice. The story closes as the tourist season in Venice ends. Eloise heads back to America to enter into an unhappy marriage, and Tibor leaves for work as a jobbing musician in Amsterdam. The narrator's later sighting of Tibor in the piazza suggests that — like Tony Gardner in the first story — he has surrendered to the forces of capitalism: 'it seemed to me that he'd lost that youthful anxiety to please, and those careful manners he had back then. No bad thing in this world, you might say' (221). If music can, at its best, offer a momentary glimpse of a better world, it is, it seems, only a fleeting escape from the pressures and constraints of the market. It is surely no coincidence that Nocturnes ends, as it begins, on the piazza - the central market square - in Venice, where the music played by the bands is a diverting tourist commodity.

'Cellists' also reflects on the differences between words and music. Can Eloise instruct Tibor in the cello through words alone? Can Ishiguro conjure the mood and feel of the American songbook in and through the written medium of the short story? Smyth observes that Eloise becomes 'the vehicle through which Ishiguro articulates his own position as a writer about a form of emotional energy that is categorically unavailable (the reader cannot hear the music described in the literary text)' (153). Smyth's interpretation reinforces the distinction between 
archive and repertoire: the written medium of the short story might try to describe the musical performance, but it can capture only silence. The ephemeral is, once more, outside of the box. The 'musical text' becomes a series of literary techniques that merely resemble musical properties. Ishiguro also asks, however, how creative forms of knowledge are transmitted. Is artistic technique - whether that of the musician or of the writer - passed on by consulting the archive, or by a more intimate commentary on technique? How, in the process of transmitting knowledge, do we move beyond the act of copying? How can we distinguish between copy and original? Are we communicating a practice or a vision? Ishiguro's story does not resolve these questions. Rather, 'Cellists' indicates that the transmission and reception of knowledge encompasses a range of modes that span from the archive to the repertoire, and that the passing on of art cannot ultimately be removed from the noise and clamour of the piazza: although Tibor's cello lessons take place in a hotel room elevated above the square, the windows of the room do not only open outward, but also let the outside in. ${ }^{6}$

\section{Late in the day}

Janeck is not a member of one of the regular bands on the piazza because he is Polish: 'Actually, I'm one of the "gypsies", as the other musicians call us, one of the guys who move around the piazza, helping out whichever of the three café orchestras needs us' (3). While the narrator of 'Cellists' is a regular band member, the story opens with his realisation of how unstable the 'family' of the band is: 'the bosom pals of today become lost strangers tomorrow, scattered across Europe, playing The Godfather theme or "Autumn Leaves" in squares and cafes you'll never visit' (190). Ray, the narrator of 'Come Rain or Come Shine', has spent his time since university teaching English abroad. He, too, has recently come to the realisation that the 'cosy, extended family of itinerant teachers' is a fiction: 'Then, before you 
know it, you're forty-seven years old, and the people you started out with have long ago been replaced by a generation who gossip about different things, take different drugs and listen to different music' (40). Across the stories of Nocturnes, Ishiguro's narrators dwell knowingly within illusory communities, opening up the question of what it means to live on the margins of structures that themselves replicate, but are not, the family.

Lisa Fluet has noted that, if Ishiguro's narrators share in common a position outside of the normative structures of family or romantic relationship, their sense of belonging arises instead from the work in which they are engaged, which takes the form of immaterial labour; that is, 'work that creates not tangible products, but rather immaterial products, such as knowledge, information, communication, a relationship, or an emotional response' (108). The result of such labour is not a stable object that can enter the archive and be preserved for future generations; rather, the characters' lives are dedicated to the iteration of ephemeral actions. Stevens, in The Remains of the Day (1989), defines himself through his years of service at Darlington Hall. Ryder, in The Unconsoled (1995), is a professional musician who is preoccupied with the demands of his perpetual concert tour. Likewise, Kathy H. in Never Let Me Go foregrounds her professional identity as a carer from the very first pages of the novel. Although the work-based communities that Ishiguro's protagonists inhabit are illusory, they offer a collective on behalf of whom the narrator speaks. Just as Kathy H.'s 'we' voices the experience of all of those who grew up at Hailsham, so Janeck's 'we' implicitly speaks for the other band members on the piazza. For Fluet, however, the community that arises from immaterial labour is limited, giving rise not to a wider commonality but to minor resentments of the distinctions between immaterial labourers of different kinds. Kathy H.'s reference to those who would resent her privileges is accordingly echoed in the hostility that Janeck describes between the gondoliers and the musicians in Venice, as well as in the 'jealousy’ directed to Tibor by the other musicians on the piazza because of his classical 
training and better prospects (191). Like Kathy, the narrator of 'Cellists' does not probe the larger inequities that render all immaterial labour precarious and unrewarded. He notes only that the other musicians tried to 'prepare [Tibor] for what lay ahead, so when the disappointments came they would not be so hard to take' (191). Like the guardians at Hailsham, the musicians' tutelage is in acceptance, in not confronting the bigger picture.

David James has justifiably noted that we might pay closer attention to the solace that is offered in Ishiguro's fictions (26). The narrator of 'Cellists' notes of the musicians that 'they liked to take the Tibors of this world under their wing, look after them a little' (191). In this, they resemble the narrators of Ishiguro's novels, who seek to give consolation, knowing that they cannot soften what is to come, but knowing too that there is value in performing the small, routine, often mundane, acts and gestures that together constitute the repertoire of care. James describes the importance of the 'almost' in relation to Ishiguro's writing: 'almost captures the provisional, often fleeting, yet nevertheless analysable attempt - an attempt enabled and embodied by style itself - to hold out the promise of consolation without necessarily fulfilling it, to draw affective blueprints for solace without underwriting their success, to tender options for redress without blithely endorsing them' (28, original emphasis). Returning to the close of 'Cellists', we might accordingly ask whether the 'bitterness' that the narrator now discerns in Tibor negates the musicians' prior concern and solicitude for him. Equally, although Gardner's nocturnal serenade of Lindy does not alter the impending divorce, might we nevertheless linger in and with the consolatory gesture that it represents, the love for Lindy that it expresses, even as it no longer underwrites the marital contract? If the setting of Venice conjures tourist commodification, it can also distil, as Sebastian Groes observes, 'a literary tradition that represents Venice as a place associated with death' (248). More particularly, in a return to that 'almost' of James' description, the literary Venice of Thomas Mann and Marcel Proust is a theatre of impending death that 
stages the question of how, and in what, we find meaning in the face of mortality. What do we turn to for consolation? How do we use, or spend, our time in what remains of the day?

James has noted that reading for consolation is also a question of form. While his analysis carefully draws out the ways in which the beauty of style works aslant distressing content, I return here to the question with which I began: namely, what it might mean to read Ishiguro's oeuvre through the lens of his short stories. Caroline Levine has called attention to the 'affordances' of form, by which she means 'the potential uses or actions latent in materials and designs' (6). Elaborating on Levine, Jacob Jewusiak has recently examined the 'affordances' of the novel for representing aging, noting that it offers 'a powerful means of capturing the persistence and transformation of identity across the lifespan' (168). Contrary to models of aging that separate a life into discrete stages, the novel captures and transmits the lived experience of 'duration', an 'interstitial temporality' that 'cuts across the lifespan' and that conveys 'the feeling of passing time' (169). Jewusiak focuses on nineteenth- and early twentieth-century works of fiction, but his analysis nevertheless pertains to Ishiguro, who has been memorably described by Patricia Waugh as an 'almost too late, late modernist' (16). This aligns Ishiguro not only with English high modernism, in his concern with the representation of interior consciousness, but also with the more expressionist landscapes of the European modernists. Ishiguro's novels display an ongoing fascination with the lived experience of time, in the retrospective narrations of Ono in An Artist of the Floating World (1986), and of Stevens and Kathy H. We can discern echoes of European High Modernism in the Kafkaesque hotel of The Unconsoled, as well as in the novel's ending: Ryder's departure in a tram for yet another European city evokes for Waugh the gesture 'of stepping out into a more convivial civic world, the cosmopolitan fraternity offered by the great European cities that was first given expression in Gogol, Haussmann, and in Baudelaire's flâneur' (20). 
The short-story form does not afford the same temporal span as the novel, but it nevertheless offers a vehicle for Ishiguro to probe the passage of time. His focus in Nocturnes remains on what Jewusiak has termed 'interstitial temporalities' (169), but these do not now cut across the lifespan but rather focus on its transitional episodes. In 'Malvern Hills', the adolescent narrator is deliberately poised at the awkward threshold of maturity, and Ishiguro notes in conversation with Groes the central questions that the story opens up: 'What should be your strategy in facing life? And how do you cope with disappointment? When is it appropriate to be angry and frustrated? And when are you just having a tantrum? The story looks at different models' (256). 'Come Rain or Come Shine' positions Ray as a surrogate adolescent son to the childless Charlie and Emily, as he looks forward to a few days of "pampering and relaxation' in their guest bedroom (41). In the farcical unravelling of the story, which entails Ray being co-opted by Charlie to save his failing marriage, similar questions are put in play to those in 'Malvern Hills'. How do we cope with disappointment? Is anger or denial the better strategy? What solace can we offer one another in the face of an unknowable future? The stories do not provide the extended retrospection that is afforded by the novels, rather, they invite reflection on transience and change by evoking a repertoire of interstitial experiences, which (re)plays the same motifs across a range of variations.

Other stories in Nocturnes reach back to the expressionist landscapes of European modernism. In Jeannette Baxter's reading of The Unconsoled, the reader is invited to enter into Ryder's 'transitory existence' by following him into the maze of the hotel and becoming disoriented with him (136). The motif of the hotel-labyrinth resurfaces in 'Nocturne', as Lindy guides Steve through the seemingly endless rooms and corridors of their hotel, in a quest to return the stolen trophy. The final story of Nocturnes ends, like The Unconsoled, in the cosmopolitan setting of the European city, and we might perhaps (re)read the tables and cafés of the Venetian square, in the spirit of an almost too-late, late modernism, as the last 
vestiges of a civic conviviality. It is, after all, through the chance encounters that they enable that the stories are brought into being. Reading Nocturnes is at once an archival exercise in recognising the familiar stylistic and thematic concerns of Ishiguro's work, and a pleasurable delight in engaging with new riffs and variations on them. Rather than preparatory exercises, the stories emerge out of, and flow from, the novels as re-workings of the standards, enlarging and expanding on their tonal and affective possibilities. Returning to Hunter's observation that the short story excels at conveying 'chronic inconsequence', Ishiguro's stories - like his novels - both succumb to and resist this notion. In the face of anticipated dread, they share a distinctively modernist fascination with the stubbornly creative and compassionate impulse that persists and that evidences our desire to find, in the eloquent words of Waugh, 'a consolation which, if it comes at all, comes almost always too late' (16).

\section{Reading the copy}

In 'Come Rain or Come Shine', Ray, left alone in his friends' house, steps out onto the roof terrace, which has a stage-like quality. He projects onto the space his fantasy of being held in a close relationship:

The sky wasn't fully dark yet, but was already filling with stars. Beyond the wall that marked the end of the terrace, I could see for miles around the windows and back yards of the neighbouring properties. A lot of the windows were lit, and the ones in the distance, if you narrowed your eyes, looked almost like an extension of the stars. This roof terrace wasn't large, but there was definitely something romantic about it. You could imagine a couple, in the midst of busy city lives, coming out here on a winter evening and strolling around the potted shrubs, in each other's arms, swapping stories about their day. (75) 
At the close of the story, Ray and Emily step out onto the terrace to dance to her Sarah Vaughan CD. For Emily, the dance symbolises her marriage to Charlie: she wants to 'just dance quietly with [her] guy', but the room continually distracts her, suggesting that she should be with a more attractive, interesting partner (84). For Ray, the dance momentarily fulfils his romantic fantasy, even as it reveals it to be an illusion: 'I held Emily close to me, and my senses filled with the texture of her clothes, her hair, her skin. Holding her like this, it occurred to me again how much weight she'd put on' (86).

The intimate dance forms a recurring motif for Ishiguro. Lindy dances slowly to her CD of Gardner's music in front of Steve when he visits her hotel room in 'Nocturne'. When Kathy H. dances to the Judy Bridgewater song in Never Let Me Go, the scene in the dorm is carefully backlit, lending it a theatrical air: 'I remember how bright it was because the curtains in our room hadn't been pulled back properly, and you could see the sun coming in in big shafts and see all the dust in the air' (70). As Kathy dances to the music her sorrow at neither having been held by a mother, nor being able to hold a future baby of her own, is explicitly staged in and through the prop of the pillow that she is holding to her chest. Although, in her reverie, Kathy feels herself to be alone, she is in fact being observed: she realises that Madame is standing in the doorway, crying. What initially seems to be a moment of empathetic encounter becomes awkward and confusing, as Madame 'turned, and the next minute I could hear her footsteps leaving the hut' (71-2). Years later, when Kathy and Tommy confront Madame, we finally learn quite how far the latter was from understanding Kathy's feelings: 'I was weeping for an altogether different reason. When I watched you dancing that day, I saw ... a new world coming rapidly. More scientific, efficient, yes ... But a harsh, cruel world' (267). In each of these scenes, the song takes on the function of what Waugh has described as a 'transitional object', which acts to console, but is also seen very differently according to where one is standing. Waugh notes: 'Ethical understanding begins 
with the recognition that, though you and I may be looking at the same object or image, the world you find in it may be a very different world from the one I find there' (24). Although, in the material of the popular song, we are dealing with the 'seemingly superficial and the stereotypical' (16), Ishiguro's late modernism manifests itself in the depth and feeling with which the mundane and the everyday is imbued.

Waugh's reading of Never Let Me Go opens up the vexed question of how to read the popular song in Ishiguro, which is not only the product of mass culture, but also, in the technologies of the record and the cassette tape, a copy. Shameem Black has aligned Never Let Me Go with surface and simulacra, arguing that it articulates 'a new aesthetics of empathy for a posthumanist age' (803). Focusing on the cassette tape — a copy of the Judy Bridgewater recording that goes missing, to be replaced by a copy of a copy that Tommy finds for Kathy in Norfolk - Black contends that Ishiguro's ethics in Never Let Me Go 'embraces the mechanical, commodified and replicated elements of personhood' (798). More than this, Black suggests that, in the complicated exchange between Kathy H. and Madame, we are shown that 'to be most human, in the world of the novel, is to recognize oneself as inhuman' (801). Rebecca Walkowitz pursues a similar line of argument, also highlighting the cassette tape. Kathy's narrative voice, filled with cliché, directs us towards the value of 'unoriginal expression' (224), and the repeated copies of cassette tapes underline that art is of interest in Never Let Me Go, not for its uniqueness, but for its networks of production and consumption. Culture describes the ceaseless circulation of copies, and what potential for originality there is lies in the new interpretation of what already exists: 'the content of art will be transformed by expansive circulation and by the local interpretations that readers impose' $(226){ }^{8}$ To read the cassette tape is to align Ishiguro with the posthuman, the surface, and the commodity.

The question that I propose to pursue is whether Nocturnes can help us to navigate these questions of surface, depth and the popular song, which pull Ishiguro alternately towards 
modernist and postmodernist affiliations. Let's turn first to the question of narrative voice. Kathy H.'s unoriginal expression is replicated in Nocturnes, as the narrators of the stories echo her conversational and clichéd figures of speech. Although the narrators of the stories differ, they all adopt the same mode of expression. That this narrative tone echoes so closely that of Never Let Me Go further compounds the issue: is Kathy H's voice an 'original' that the stories copy, or does her narrative voice render the question of an original redundant? Reading the stories of Nocturnes in relation to one another raises the same interpretative dilemma: as voices, images and themes repeat across the narratives, it becomes impossible to distinguish between copy and original. The collection becomes a network of circulation, even as it represents the networks of consumption through which culture is circulated, transmitted and shared. The reader's attention is drawn to what Walkowitz has termed 'comparative forms': we are looking for 'the echo, the clone, the list, the series, and the translation' (235). In this sense, Nocturnes might suggest that the short-story collection, rather than the short story per se, is of particular interest to Ishiguro as a means of developing his stylistic and thematic interest in the copy: it affords a repertoire of motifs, which themselves tap into and reproduce the broader repertoire of 'standards' from and through which culture is produced.

Is this, however, to depart too hastily from the 'depth' model of the archive? Although the stories of Nocturnes do not have the extended retrospection afforded to Etsuko in A Pale View of Hills (1982), for example, they retain an interest in how we experience ourselves in terms of moments and memories that cut across the life course. I have noted in 'Crooner' that Janeck's memories of his Polish childhood are constructed from a repository of Gardner's album covers, as well as his mother's intense affective attachment to them. Gardner's serenading of Lindy from the gondola likewise suggests that his inner life is stitched together through the repertoire of the American songbook. 'I Fall in Love Too Easily' captures the beginning of his relationship with Lindy: shortly after their marriage, they made love in their 
London hotel room with the maid cleaning the suite next door. The maid turned on the radio and Chet Baker was singing, 'nice and slow and mellow. And Lindy and me, we just lay there across the bed together, listening to Chet singing' (23). On the one hand, we could take Ishiguro to be saying that our repertoire of emotion is fundamentally replicated, that our most intimate expressions of feeling are mere copies of, or variations on, the popular standards. But there is an undeniable tenderness, both in Gardner's performance and in Lindy's response, which is not entirely captured by this reading. It surfaces again in Janeck's memories of his mother, which prompts him to buy her Gardner's records whenever he finds an opportunity to do so. James has pertinently observed of Never Let Me Go: 'Ishiguro provokes readers to reflect on their own parameters of sympathy and judgment - most notably, on our grounds for subjecting to critique what his characters utilize to console' (26). While James has in his sights here critical tendencies to dismiss characters' wishful narratives of solace as modes of collusion, this might perhaps also pertain to an ingrained cultural elitism. If Ishiguro's characters use the ephemeral repertoires of popular culture as the material for consolation, then does our tendency to subject them to critique signal an ongoing difficulty in mediating productively between archive and repertoire - in seeing the album cover of Gardner's hit record as the material not only for consolation, but also for inclusion in that cardboard box under the desk, that forms the repository of the archive of the future?

\section{Conclusion}

Speaking of Nocturnes in interview with Alex Clark, Ishiguro has positioned the writing of the collection in relation to The Buried Giant (2015). His wife, Lorna, responded to the first draft of The Buried Giant by saying that Ishiguro would have to start again from the beginning. In the break between completing the first draft and returning to the novel, Ishiguro 
completed the five stories of Nocturnes. Ishiguro thereby positions the short stories as a temporary distraction from The Buried Giant, as both secondary to and preparatory for the next novel. ${ }^{7}$ In this essay, I have sought to suggest alternative modes of reading Nocturnes in relation to Ishiguro's broader oeuvre, complicating the prevailing idea of the short story as juvenilia and as practice piece, and opening up some of the distinctive affordances of the form in relation to Ishiguro's central themes and preoccupations. Further, I have indicated that the interrelated short-story collection, which sits in the interstices between short story and novel, as well as between literary fiction and musical album, is a mode that opens up Ishiguro's oeuvre beyond the novels, to include his song-writing collaborations.

This essay's mediations between archive and repertoire tap into, and reach out towards, broader discussions in literary studies about depth and surface reading, specificity and universalism, the critical and the reparative. In a variety of contexts, critics are grappling with the relation and balance between these terms. The Ishiguro archive at the Harry Ransom Center will undoubtedly usher in a new wave of readings of his work, generating valuable insights into the genesis of Ishiguro's writing, and his processes of drafting and composition. In closing, however, I return to Levine's discussion of affordances, in which she remarks: 'Rather than asking what artists intend, or even what forms $d o$, we can ask instead what potentialities lie latent - though not always obvious - in aesthetic and social arrangements' (6; original emphasis). The literary archive is a material space and it is composed of objects; it is also a means of organising things. My question in this essay has been whether the repertoire might represent a 'potentiality' that lies 'latent' in the archive. If so, then in what ways, and with what effects, might it be animated, in the ongoing project of reading and interpreting Ishiguro's literary oeuvre? 


\section{Notes}

${ }^{1}$ The Harry Ransom Center acquired the archive in 2015, two years prior to Ishiguro being awarded the Nobel Prize for Literature.

${ }^{2}$ Ishiguro made contact with Kent after he chose her recording of 'They Can't Take That Away From Me' as one of his tracks on Radio 4's Desert Island Discs. He has since contributed to her albums Breakfast on the Morning Tram (2007), Dreamer in Concert (2011), The Changing Lights (2013) and I Know I Dream (2017), in addition to writing the liner note for In Love Again (2003).

${ }^{3}$ See, for example, David Szalay's All That Man Is (2016) and Zoe Gilbert's Folk (2018). Ishiguro's hesitation to describe his collection as short stories also echoes the recent marketing of interconnected short-story collections as novels. A more recent American example is Garth Greenwell's Cleanness (2020), which is similarly poised between novel and short-story collection. Like Ishiguro, Greenwell has evoked a musical analogy for its arrangement and composition, evoking the Schubert Lieder cycle as his inspiration.

${ }^{4}$ Although Ishiguro observes in the interview that 'you sometimes don't want a track released as a single' (no pagination), the short story 'Come Rain or Come Shine' has now been published as an independent volume in the Faber Shorts series (2019) and is also anthologised in Philip Hensher's collection of contemporary British short stories (2018).

${ }^{5}$ The replacement of CDs by the iPod underlines Ishiguro's point: for the reader, the technology of transmission current in the story is now in the process of becoming obsolete.

${ }^{6}$ Although it lies beyond the scope of this essay, an interesting question arises as to whether, read through the lens of the short stories, there is a distinction between the more 'musical' 
works in Ishiguro's oeuvre and those that explore the production and transmission of visual art:

${ }^{7}$ The Buried Giant is interested in the simultaneous comfort and terror of memory loss. Axl and Beatrice dread more than anything else the vanishing into the surrounding fog of their repertoire of shared routines and habits that has been accrued over a lifetime of marriage.

\section{References}

Aitkenhead, Decca. 'The G2 Interview: Kazuo Ishiguro'. The Guardian. 27 April 2009. https://www.theguardian.com/books/2009/apr/27/kazuo-ishiguro-interview-books

Baxter, Jeannette. 'Into the labyrinth: Ishiguro's surrealist poetics in The Unconsoled'. Kazuo Ishiguro: New Critical Visions of the Novels. Ed. Sebastian Groes and Barry Lewis.

Basingstoke: Palgrave, 2011. 133-143.

Black, Shameem. 'Ishiguro's Inhuman Aesthetics'. Modern Fiction Studies 55.4 (2009). 785 807.

Clark, Alex. 'Kazuo Ishiguro's turn to fantasy'. The Guardian, 19 February 2015. https://www.theguardian.com/books/2015/feb/19/kazuo-ishiguro-the-buried-giant-novelinterview

Enniss, Stephen. 'Taking Note of the Kazuo Ishiguro Archive', 15 June 2016. https://sites.utexas.edu/ransomcentermagazine/2016/06/15/taking-note-of-kazuo-ishiguro$\underline{\operatorname{archive/}}$

Fluet, Lisa. 'Immaterial Labours: Ishiguro, Class, and Affect'. NOVEL: A Forum on Fiction 40.3 (2007). 265-88. 
Greenwell, Garth. Cleanness. London: Picador, 2020.

Gilbert, Zoe. Folk. London: Bloomsbury, 2018.

Groes, Sebastian and Barry Lewis. 'Introduction: “It’s good manners, really” - Kazuo Ishiguro and the Ethics of Empathy'. Kazuo Ishiguro: New Critical Visions of the Novels. Ed. Sebastian Groes and Barry Lewis. Basingstoke: Palgrave, 2011. 1-10.

Groes, Sebastian. 'The new seriousness: Kazuo Ishiguro in conversation with Sebastian Groes.' Kazuo Ishiguro: New Critical Vision of the Novels. 247-64.

Hensher, Philip, ed. The Penguin Book of the Contemporary British Short Story. Harmondsworth: Penguin, 2018.

Hungerford, Amy. Making Literature Now. Stanford, CA: University of Stanford Press, 2016.

Hunter, Adrian. The Cambridge Introduction to the Short Story in English. Cambridge: Cambridge University Press, 2007.

Ishiguro, Kazuo. A Pale View of Hills. London: Faber, 1982. An Artist of the Floating World. London: Faber, 1986. . The Remains of the Day. London: Faber, 1989. . The Unconsoled. London: Faber, 1995. . 'Liner Note'. In Love Again. 2003. https://www.staceykent.com/album.html . Never Let Me Go. London: Faber, 2005. . The Buried Giant. London: Faber, 2015. 
. My Twentieth Century Evening and Other Small Breakthroughs. London: Faber, 2017.

. Come Rain or Come Shine. London: Faber, 2019.

James, David. Discrepant Solace: Contemporary Literature and the Work of Consolation. Oxford: Oxford University Press, 2019.

Jewusiak, Jacob. Aging, Duration and the English Novel. Cambridge: Cambridge University Press, 2020.

Levine, Caroline. Forms: Whole, Rhythm, Hierarchy, Network (Princeton and Oxford: Princeton University Press, 2015.

Matthews, Sean. “'I'm Sorry I Can't Say More”: An Interview with Kazuo Ishiguro'. Kazuo Ishiguro: Contemporary Critical Perspectives. Ed. Sean Matthews and Sebastian Groes. London: Continuum, 2009. 114-25.

Reynier, Christine. Virginia Woolf's Ethics of the Short Story. New York: Palgrave, 2009.

Shaffer, Brian W. "'Somewhere Just Beyond the Surface of Things: Kazuo Ishiguro's Short Fiction'. Kazuo Ishiguro: Contemporary Critical Perspectives. Ed. Sean Matthews and Sebastian Groes. London: Continuum, 2009. 9-19.

Smyth, Gerry. “"Waiting for the performance to begin”: Kazuo Ishiguro’s musical imagination in The Unconsoled and Nocturnes'. Kazuo Ishiguro: New Critical Visions of the Novels. Ed. Sebastian Groes and Barry Lewis. Basingstoke: Palgrave, 2011. 144-56.

Szalay, David. All That Man Is. London: Vintage, 2016.

Taylor, Diana. The Archive and the Repertoire. Durham, NC and London: Duke University Press, 2003. 
Tonkin, Boyd. 'Kazuo Ishiguro: The Big Interview'. The Independent. Friday 8 May 2009. https://www.independent.co.uk/arts-entertainment/books/features/kazuo-ishiguro-the-writers$\underline{\text { musical-short-story-collection-belies-his-love-for-warrior-tales-1680747.html\#r3z-addoor }}$ Waugh, Patricia. ‘Kazuo Ishiguro's not-too-late modernism'. Kazuo Ishiguro: New Critical Visions of the Novels. Ed. Sebastian Groes and Barry Lewis. Basingstoke: Palgrave, 2011. 13-30.

Walkowitz, Rebecca. 'Unimaginable Largeness: Kazuo Ishiguro, Translation, and the New World Literature'. Novel: A Forum on Fiction 40.3 (2007). 216-39. 